\title{
DO WET SUITS AFFECT SWIMMING SPEED?
}

\author{
Luise PARSONS, MB, BS, MSc* and S. J. DAY, BSc, FSS** \\ *Department of Community Medicine, City and Hackney Health Authority \\ * *Department of Clinical Epidemiology, The London Hospital Medical College
}

\begin{abstract}
A randomised cross-over trial was conducted to see if wet suits increase swimming speed - a question which has been fiercely debated in the fast-growing endurance sport of Triathlon. Sixteen swimmers volunteered to undertake two 30 minute swims, one with and one without a wet suit. With wet suits the subjects swam an average of 24.9 lengths of a $66 \mathrm{~m}$ pool. Without wet suits they swam 23.2 lengths. A $95 \%$ confidence interval for the difference is from 0.8 to 2.6 lengths ( $p<0.001$ ). This result suggests that regulations about the use of wet suits must be agreed internationally to ensure equal competition whilst promoting the health and safety aspects of sport.
\end{abstract}

Key words: Wet suits, Swimming speed, Cross-over trials.

\section{INTRODUCTION}

Triathlon is a fast-growing endurance sport that usually involves an open water swim, cycling and running. The distances vary from the classic Ironman of a 2.5 mile swim, 112 mile cycle ride and a marathon $(26.2$ mile) run, to shorter events of $\mathbf{4 0 0}$ metres swimming, 25 mile cycle and 7 mile run. Triathlon started in Hawaii in 1978 and the first event in Britain was held in 1983. There were 24 British events in 1984 and over 48 in 1985. The number of members of the British Triathlon Association doubled in 1985 alone (Hunter and Kirschbaum, 1985).

One of the challenges of Triathlon is that the body build suitable for marathon running is disadvantageous during long distance open water swimming and that suitable for open water swimming is unsuitable for cycling and running. Few elite, male, long-distance runners will have more than $5 \%$ body fat (Costill et al, 1970), whereas long-distance swimmers will have upwards of $25 \%$ (Pugh and Edholm, 1955). Triathletes tend to have an average of $10-12 \%$ body fat (Labman, 1985), with slightly more in those coming from a swimming background. Many try to lose weight so that they are faster on the cycling and running stages but this is at the expense of endurance in the water. In warmer climates this would not matter over the distances usually covered in Triathlon but becomes significant when water temperatures are below $16^{\circ} \mathrm{C}$ as they were for several events in Britain in 1985. The most notable example was in the National long-course championship in August 1985 where 48 of the 117 entrants $(41 \%)$ were forced to withdraw from the 2 mile swim because of hypothermia.

One way of compensating for the cold is to wear a wet suit. Modern wet suits made of neoprene can be designed for a variety of different sporting purposes. They trap a thin layer of water which is rapidly warmed by the body and then insulates in the same way as body fat. Wet suits protect against hypothermia and therefore are important for safety reasons.

Address for correspondence:

Dr. Luise Parsons, MB, BS, MSc

Medical Adviser to the British Triathlon Association

Department of Community Medicine

St. Leonard's

Nuttall Sreet

London N1 $5 L Z$
The swimming rules of the British Triathlon Association state that "no fins, paddles, snorkels or flotation devices shall be allowed". The debate in 1985 was whether wet suits constituted a floatation device, with the rule being interpreted differently by the executive committee, race directors and competitors. The increased buoyancy was acknowledged recently in an article by an American Triathlete who wrote: "It is comforting to approach a long rough-water swim in a warm buoyant second skin, knowing you will not sink" (Harper, 1985).

Swimmers objected to the use of wet suits because they believed thai buoyancy increased swimming speed.

The debate continued throughout the bad weather of the British summer of 1985, with every event marred by the controversy over wet suits. However, in the middle of all the debates there were very few facts and no evidence that wet suits actually affected swimming speed.

Clearly a scientific study was required. As the effect might be expected to vary between different groups of Triathletes (elite vs novice, thin vs fat, male vs female) an epidemiological approach was chosen rather than the physiological one more common in sport. A randomised, cross-over trial of wet suits and swimming speed was undertaken.

\section{METHODS}

Sixteen Triathletes (14 males, 2 females) volunteered to take part in a two-period, cross-over trial; each to swim once with and once without a full length, sleeveless wet suit. A fixed time of $\mathbf{3 0}$ mins for each swim was set (rather than a fixed distance) as this was considered long enough for the effects of the cold to take effect but would still be well within the capabilities of all the athletes taking part. A further consideration was that they would only have three hours to recover from the morning swim before beginning the second stage of the trial. Each swimmer was assigned randomly to either:

Group I: who swam for $\mathbf{3 0}$ mins at 10 a.m. wearing a wet suit and then again at 1 p.m. without a suit, or

Group II: who swam at 10 a.m. without and at 1 p.m. with a wet suit (again for 30 mins each time). See Fig. 1.

During the interval the Triathletes had hot food and dry clothing available. 


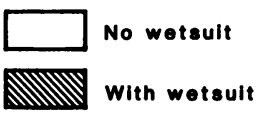

Group I n 7

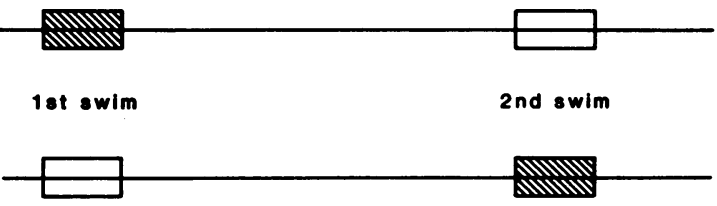

roup II n 8

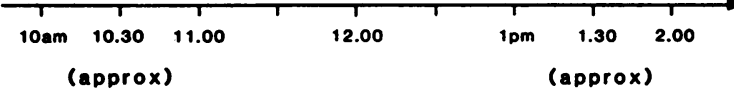

Fig. 1: Schematic diagram showing times of swims and use of wet suits in each of the two groups.

Age, sex, weight, height and resting pulse rate were recorded and percentage body fat was estimated by the method of Durnin and Womersley (1974) from skinfold thickness measured at four sites with Holtain Calipers. Past medical history, family history and any medicines taken were also recorded. The number of Triathlons completed, level of achievement and personal best times attained for a 1 mile swim, 25 mile cycle ride and half marathon run were noted. Each was asked whether or not they normally wore a wet suit when competing and whether they thought it affected swimming speed.

The trial took place at the end of September 1985 when the weather was unusually clement with hazy sunshine, clearing a little for the second swim. The water temperature was approximately $18^{\circ} \mathrm{C}$ throughout.

An open air pool, 66 yards long, was used and times were recorded after every two lengths until 30 mins had elapsed. Seven competitors swam with suits in the morning (Group I) and nine used them for the afternoon swim (Group II). During the first swim, one competitor not wearing a suit withdrew after 16 lengths $(21 \mathrm{mins})$ due to severe cold. In the second swim, he deliberately withdrew after the same distance (19 mins 23 secs). A second swimmer, also from Group I, who covered 24 lengths in the morning (31 mins 55 secs) withdrew after 16 lengths (22 mins 50 secs) in the afternoon complaining that he had eaten too much. Both of these individuals were removed from the analysis which was then carried out in the standard manner (Hills and Armitage, 1979).

\section{RESULTS}

The personal characteristics and opinions of the 12 males and 2 females who completed the trial are summarised in Table I which shows that the volunteers represented a wide range of physical and athletic abbilities. In addition, age, weight, body fat and experience are equally distributed between the two groups. Of particular importance was the response to the question 'Do you think wet suits increase swimming speed?' Seven thought that they did and six thought they did not; one had no opinion. This does not eliminate bias but if their answers were accurate then at least opinions were evenly balanced for and against.

The mean distance swum with wet suits in the morning swim was $24.7 \pm 4.2$ lengths (mean \pm SD) and without suits was $23.4 \pm 4.0$ lengths. In the second swim, the mean distance with wet suits was $24.8 \pm 4.6$ lengths and without was $23.1 \pm 4.3$ lengths. Of interest was the fact that all of the swimmers performed better with a suit than without. The overall improvement was 1.7 lengths from a mean of 23.2 to 24.9 with a $95 \%$ confidence interval for the improvement being from 0.8 to 2.6 lengths, $p<0.001$.

TABLE I

Personal characteristics and opinions of the subjects with regard to the influence of wet sults on swimming speed

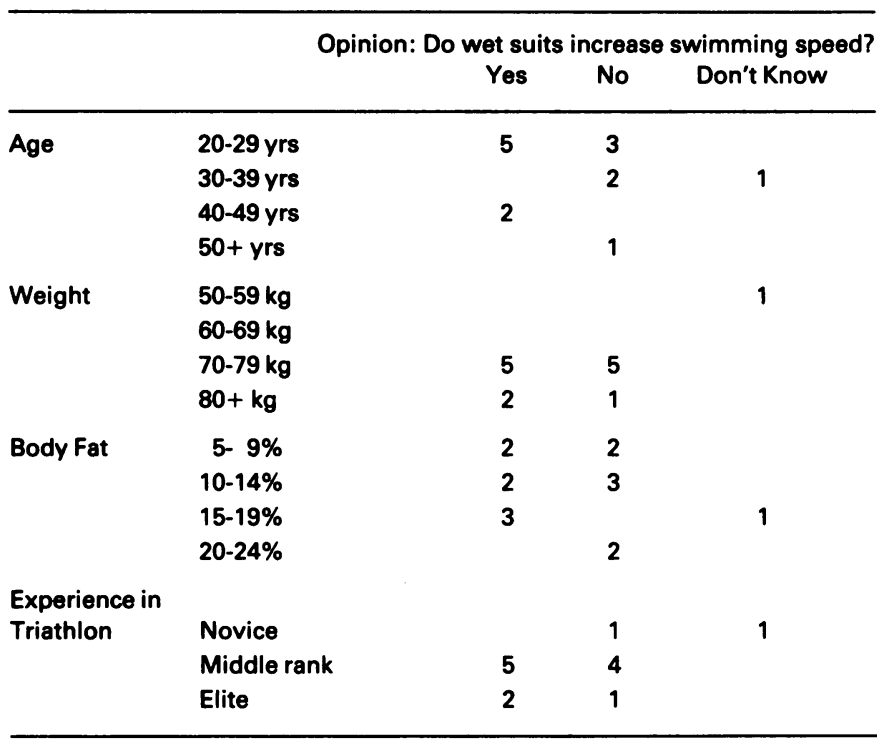

There was concern about the possibility of a large period effect (i.e. a tendency to swim slower during the second swim than the first). The mean distance covered in the first swim was $24.0 \pm 4.0$ lengths and in the second swim, the mean was $24.1 \pm 4.4$ lengths. The $95 \%$ confidence interval for this difference is from -0.6 to 1.1 lengths suggesting a slight tendency to swim faster in the second swim. No practical significance was attributed to this.

\section{DISCUSSION}

This study was designed to help the British Triathlon Association to formulate rules about the use of wet suits in the sport. The results of the trial demonstrate conclusively that wet suits do increase swimming speed by about $7 \%$. This gave an average advantage of 100 metres in a 1400 metre swim, the improvement being seen in a sample of Triathletes with a wide range of physical characteristics and athletic abilities. There are two possible interpretations of this effect. Firstly, swimmers without wet suits swim slower because of the cold or, secondly, those with wet suits swim faster because of increased buoyancy. We are not able to suggest which of these factors is of greater importance from this study. However, experience of wearing a wet suit and observation during the trial suggest that buoyancy may be more important.

Supporters of wet suits argued that the swim section was meant to test swimming rather than the abiity to withstand cold and that safety in cold water was a prime consideration. They also point out that if an expensive bike could be bought to improve performance, why not allow wet suits which are clearly indicated for safety reasons even if they do improve performance? Those against wet suits say that the nature of Triathlon does mean battling against the elements including cold water, that the buoyancy of wet 
suits is an aid to swimming and that the advantage gained continues into the cycling stage as athletes do not have to spend the first few miles warming up. The pro-wet suit lobby counter that any advantage gained would be lost by a slow transition time between the swim and the cycle. However, the magnitude of the advantage conferred by wet suits may outweigh this.

The evidence from this trial has made the decision about what kind of wet suits to allow in Triathlon in Britain more difficult. Medical advice remains that wet suits should be permitted for health and safety reasons. However, a mean advantage of $7 \%$ is most significant in international competition. If wet suits are unrestricted they will become a standard item of equipment, the assistance being limited only by finance.

Regulaions about the use of wet suits must be agreed internationally to ensure equal competition whilst promoting the health and safety aspects of the sport.

\section{ACKNOWLEDGEMENTS}

The authors would like to thank the sixteen Triathletes who volunteered for the trial, the committee of the British Triathlon Association for their support and the lifeguards of Newham Leisure Services who recorded the results.

\section{References}

Costill, D. L., Bowers, R. and Kammer, W. F., 1970 "Skinfold estimates of body fat among marathon runners". Med.\& Sci.Sports 2: 93.

Durnin, J. V. G. A. and Womersley, J., 1974 "Body fat assessed from tota body density and its estimation from skinfold thickness: measurement on 481 men and women aged from 16 to 72 years". Br.J.Nutr. 32: 77.

Harper, D., 1985 "Wet behind the seams: A look at wet suits". Triathlete Magazine 28: 14.

Hills, M. and Armitage, P. M., 1979 "The two-period cross-over clinical trial". Br.J.Clin.Pharmacol. 8: 7-20.

Hunter, A. and Kirschbaum, E., 1985 "Swim + Bike + Runs Triathlon: The Sporting Trinity". Allen, London p. 13.

Labman, 1985 "Body fat". Triathlete Magazine 12: 15.

Pugh, L. G. and Edholm, D. G., 1955 "The physiology of channel swimmers". Lancet 2: 761-767.

\section{BOOK REVIEW}

Title:

\section{BAILLIÉRE'S HANDBOOK OF FIRST AID}

Authors:

Norman G. Kirby and Stephen J. Mather

Publishers:

Bailliére Tindall, London

Price: $\mathbf{f 6 . 9 5}$

360 pages. Index. Numerous line drawings

ISBN 0-7020-1097-9

Because of the efficient and centralised Ambulance Service in Britain's National Health Service, most of our recent first aid books omit much of the detailed casualty management given in the times of the two World Wars, leaving the main advice to "Tie his legs together and dial 999". It is therefore a welcome change to read a book that does not assume that such help is always at hand, and that in certain circumstances more may have to be done, in mountains, at sea, or in a major disaster. All the basic first aid in such as the St. John Handbook is covered, but this book goes a long way beyond the basics. Part I is a general introduction to first aid principles, resuscitation, emergency childbirth, action at road traffic accidents and in major disaster situations. Part II is an elementary introduction to anatomy and physiology as applied to emergency treatment which is useful for the layman, but the overuse of phrases such as "... is called ..." or "... known as ..." tend to make the approach rather unsophisticated. These words are omitted in the section on the eye, which makes me think these pages were written more recently and not taken from earlier editions. The description of the 11th and 12th ribs, "to which only muscles are attached" ignores their vertebral articulation, and the illustration of the biceps as two completely separate muscles acting only as elbow flexors without any supination is also misleading.

Part III is on clinical practice, and generally is excellent, though a few minor additions could be made with advantage. Shock is well described, including myocardial infarction, but there can be silent Ml's that do not give the usual severe pain. On wound closure steristrips and butterfly strapping could be mentioned as being within the realm of the first aid worker; not every incised wound needs to be sutured by a doctor. The first sentence on tetanus infection implies that death is an inevitable result instead of a mortality of $20 \%$, though the lesson of early and repeated immunisation is stressed. The traditional description of an open fracture, with bone ends protruding through the skin wound is given but there is no mention of the obvious "closed" fracture but with a whole-skin-thickness wound hidden elsewhere on the same segment of the limb as the fracture which needs treating surgically as an open fracture.

These minor points do not detract from a comprehensive book, in which one may pick out most useful sections on sports injuries (and we are pleased to note that the first named author was a member of our Association for several years) and his long Army experience is reflected in the section on war and urban terrorist injuries and nuclear disasters, so relevant with Ulster and Chernobyl in mind. The chapter on poisons is brought up to date, and includes industrial poisons, and the section on head injuries gives in detail the nationally accepted Glasgow Coma Scale, new to many of us no longer in hospital practice. New dressings are described, and developments in the design and use of stretchers (though not the Thomas' Mountain Rescue Stretcher). Techniques of splint application are given, including the Thomas' splint, so useful in leg fractures remote from ambulance road-head.

The book is highly recommended for those teaching advanced first aid, and I am sure that many doctors as well as nurses and physiotherapists could, like myself, learn a great deal from it. 